\title{
Advances in oil condition monitoring permits preventive maintenance before damage occurs assuring asset protection and achieving theoretical component lifetimes
}

\author{
Manfred Mauntz ${ }^{1, a}$, Ulrich Kuipers ${ }^{2}$ and Jörn Peuser ${ }^{1}$ \\ ${ }^{1}$ cmc Instruments GmbH, Hauptstrasse 388, 65760 Eschborn, Germany \\ ${ }^{2}$ South Westphalia University of Applied Sciences, Haldener Strasse 182, 58095 Hagen, Germany
}

\begin{abstract}
Résumé. Système de diagnostic des huiles en ligne basé sur le Web pour la première identification de détection de dysfonctionnement et usure prématuré des machines tournantes dans l'industrie et particulièrement des boîtes de vitesse d'énergie éolienne par des fentes (craquements) de gravure blanches est présenté. L'approche novatrice utilise la détection de capteur de vieillissement de produit chimique du lubrifiant et ses additifs en raison des conditions d'opération critiques. Le système de diagnostic en ligne mesure les composants de l'impédance complexe spécifique d'huiles.
\end{abstract}

\section{Basic principles of the sensor system}

With the WearSens ${ }^{\circledR}$ unit, components of the complex impedances $\mathrm{X}$ of oils, in particular the specific electrical conductivity $\kappa$ and the relative permittivity $\varepsilon_{\mathrm{r}}$ as well as the oil temperature $\mathrm{T}$ are measured [1-3]. The values $\varepsilon_{\mathrm{r}}$ and $\kappa$ are determined independently of each other. Figure 1 shows the base sensor with a 1" connector block ready for robust industrial installation and the communication unit with standard RS232 and LAN interface.

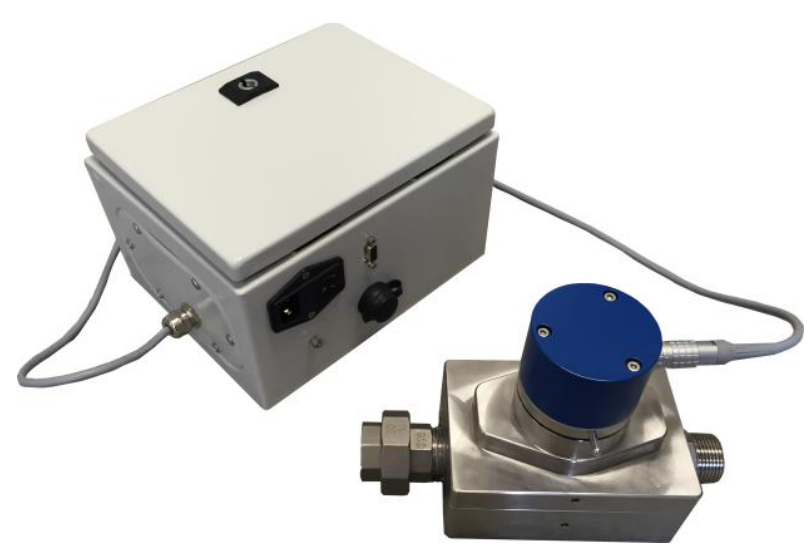

Figure 1. Sensor system with 1" connector block and communication unit.

Oils are electrical non-conductors. The electrical residual conductivity of pure oils lies in the range below $1 \mathrm{pS} / \mathrm{m}$. The conductivity of various materials is illustrated in figure 2 . The conductivity range of the presented sensor system is marked in green. It starts below the conductivity of the distilled water. For comparison, the electrical conductivity of the electrical non-conductor distilled water is larger by six orders of magnitude.

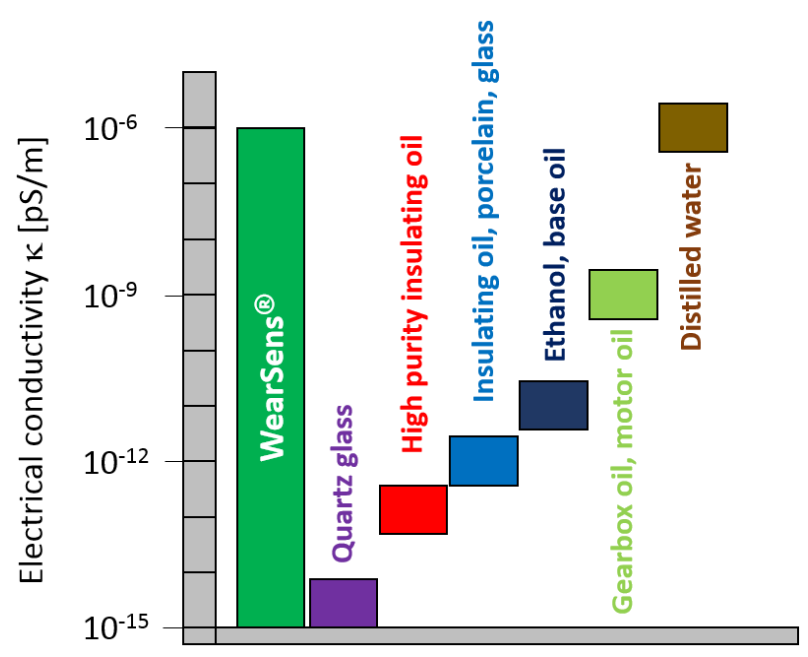

Figure 2. Conductivities of liquids and solids, measurement range of the presented sensor system is marked in green.

Abrasive (metallic) wear, ions, broken oil molecules, acids, oil soaps, etc., cause an increase of the oil conductivity $\kappa$. It rises with increasing ion concentration and mobility. The electrical conductivity of almost all impurities is high compared with the extremely low corresponding property of original pure oils. A direct connection between the degree of contamination of oils and the electrical conductivity is found. An increase of the electrical conductivity of the oil in operation can thus be interpreted as increasing wear or contamination of the lubricant. The aging of the oil is also evident in the degradation of additives. The used additives reveal high conductivity compared with the oil.

In figure 3 the data acquisition and data processing in the sensor system is sketched with the field data acquisition, data processing and signal output. The rectangular boxes

\footnotetext{
amrm@cmc-instruments.de 
represent autonomous functional units with defined responsibilities. They are characterized by inputs and feedback-free outputs. The individual instances communicate with each other via the data spaces shown as circles. Data flow is characterized by means of arrows between data spaces and instances. The instance network allows a static interpretation of the catchment area of the individual functional units.

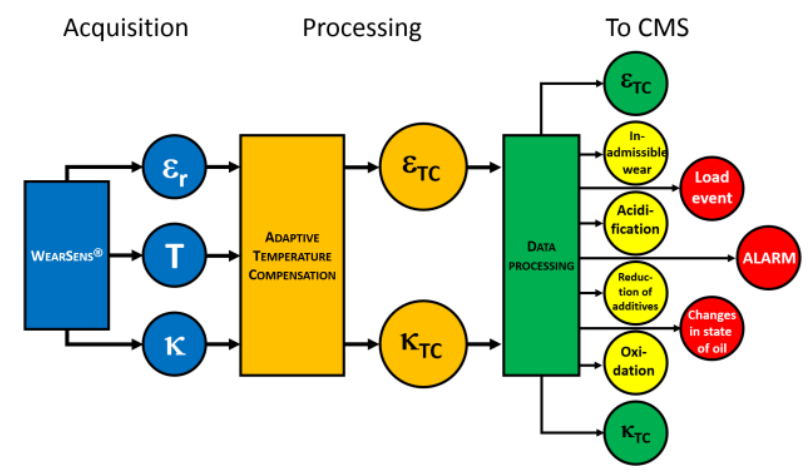

Figure 3. Data flow graph of the sensor system.

\section{Measurement accuracy temperature compensation}

Ion mobility and thus, electrical conductivity $\kappa$ are dependent on the internal friction of the oil and therefore, also on its temperature. The conductivity $\kappa$ of the oil increases with temperature. The type of contamination and its temperature dependence cannot be assumed to be known. To improve the comparability of measurements, a self-learning adaptive temperature compensation algorithm is necessary. A change of the oil quality can then be assessed by the temperature compensated conductivity value, even though the specific contamination is not determinable. The relative permittivity is measured with the same basic sensor arrangement as used for the determination of the electrical conductivity. Figure 4 shows the effect of temperature compensation.

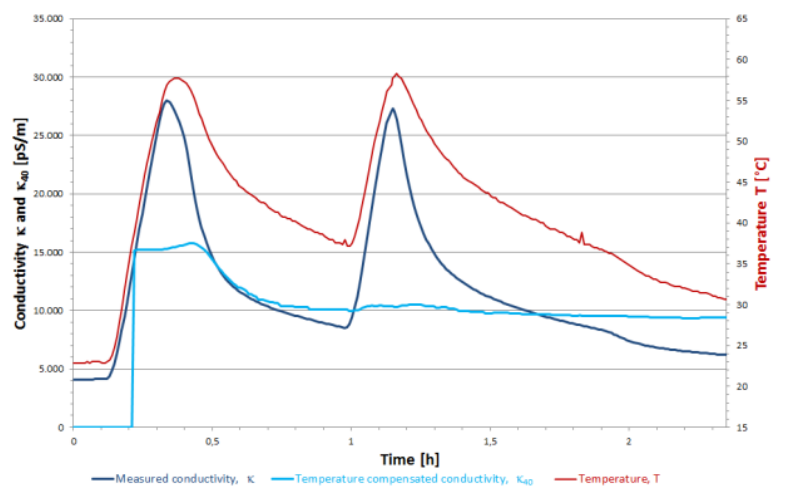

Figure 4. Effect of the temperature compensation algorithm

While the conductivity $\kappa$ changes significantly with temperature, the temperature compensated conductivity $\kappa_{40}$ stays nearly constant.

\section{Model for the condition monitoring of additivated lubricating oils}

The model is based on the theory that the consumption of the additives is directly correlated with the reduction of the electrical conductivity and permittivity of the oil. The gradient, i.e. the time derivative, of the conductivity or the dielectric constant progression respectively represents a measure of the additive degradation and consumption. The full additive degradation is indicated by the slope of zero (bathtub curve). Then the measurement signal increases further with increasing pollution, water entry, etc.

Fig. 5 schematically shows the temperature compensated time curve of the permittivity of additivated oil continuously contaminated by the addition of wear debris, water or oil acids from chemical aging:

\section{Sector A:}

Polar additives are combining with impurities, particles, acid and soap products, which reduces the additive content in the lubrication oil and result in a decrease of the relative permittivity $\varepsilon_{\mathrm{r} 40}$.

\section{Sector B:}

Probably total reduction of additives.

\section{Sector C:}

Due to the lack of additive components new generated polar elements can't be chemically neutralized anymore, which leads to an increase of the relative permittivity $\varepsilon_{\mathrm{r} 40}$.

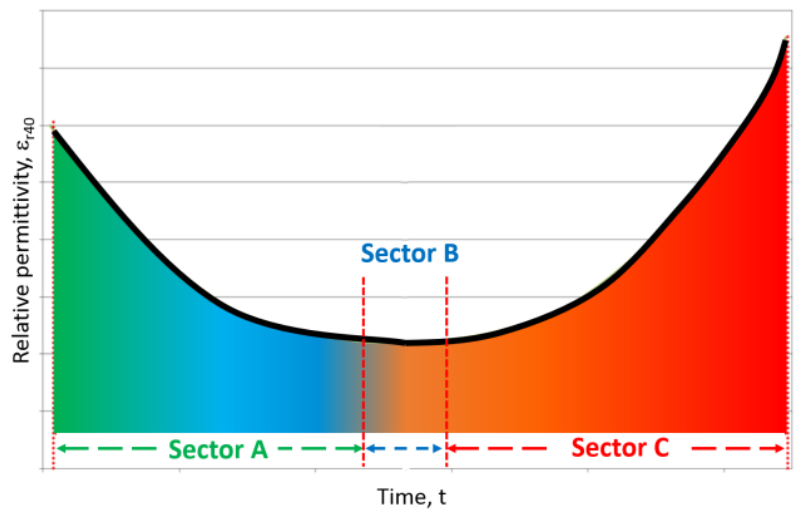

Figure 5. Model of the temperature compensated permittivity.

\section{Application: Hydraulic actuator}

This section demonstrates the oil sensor application for the condition monitoring of a hydraulic actuator used for wind turbine testing. The basic setup of this blade fatigue test is depicted in figure 6. During the Ground Resonance Excitation (GREX) the hydraulic actuator applies automated cyclic loading to the blades at its resonant frequency [4]. 


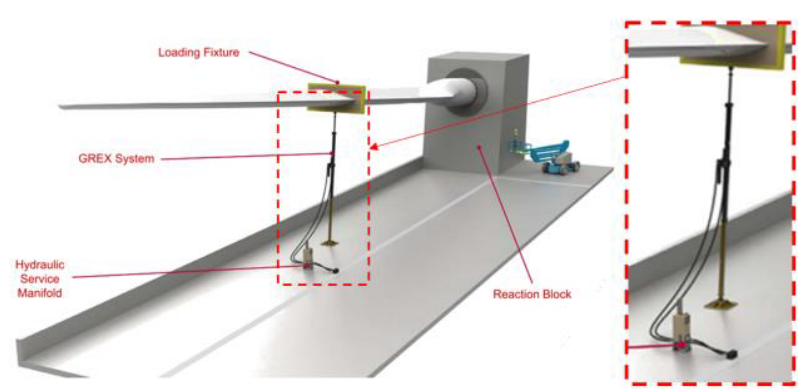

Figure 6. Rotor blade test stand with GREX [4].

The schematics of the hydraulic oil flow is shown in figure 7. The hydraulic oil tank contains about 1900 Litre; a flow rate of 600 Litre/minute is set between the tank and the hydraulic service manifold (HMS). The HMS regulates the cyclic hydraulic pressure on the actuator, to excite the rotor blade at the resonance frequency. A lower flow rate, $100 \mathrm{ml} /$ minute, is used in the oil cycle with the WearSens sensor. By these flow settings it is assured that there is sufficient oil exchange in each oil cycle via the HPU tank.

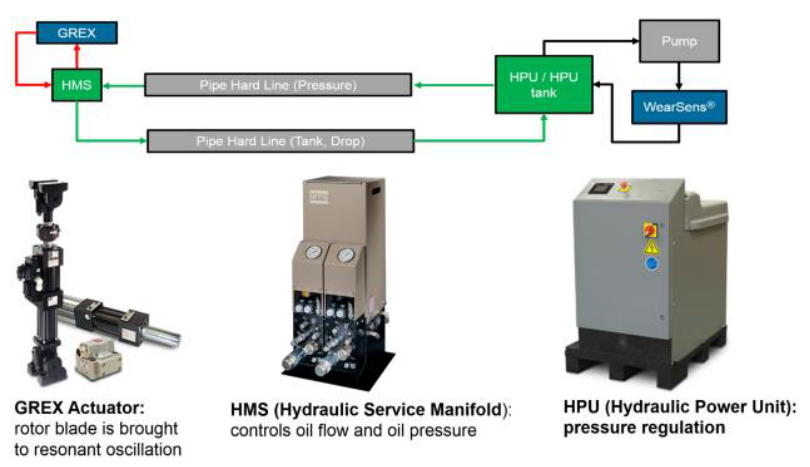

Figure 7. Scheme of the three hydraulic oil cycles at the GREX installation, including single component descriptions of GREX, HMS and HPU.

The presented data in figure 8 and 9 was recorded during a long term rotor blade fatigue test run; the oil sensor system was installed to continuously monitor the hydraulic oil quality, for preventing the actuator from damage.

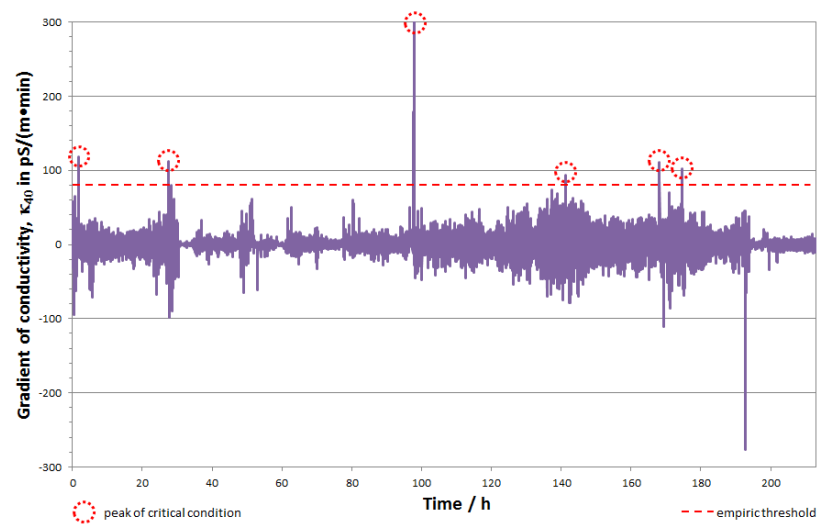

Figure 8. Gradient of the temperature compensated conductivity over time.

The data in figure 8 shows the gradient of the temperature compensated electrical conductivity $\kappa_{40}$ over time: a continuous increase during normal operation of the hydraulic actuator system has a lower gradient than critical operation conditions, which are visible in sharp peaks, highlighted with red circles. A threshold analysis can be used to minimize the events of critical operation conditions to enable long term stable operation.

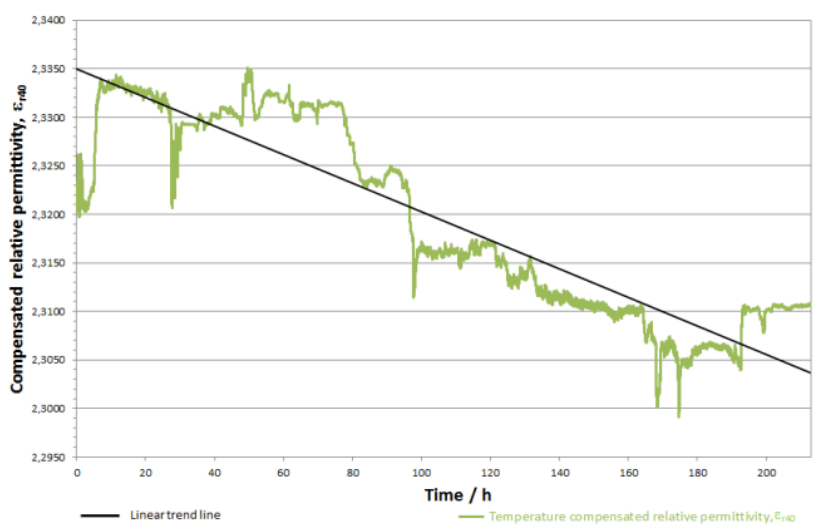

Figure 9. Temperature compensated relative permittivity over time

The decreasing trend line of the relative permittivity in figure 9 signals the continuous consumption of polar additives in the hydraulic oil due to the actual load over the complete measurement run. Limit settings in the relative permittivity $\varepsilon_{\mathrm{r} 40}$ and the corresponding gradient of $\varepsilon_{\mathrm{r} 40}$ can be used to perform condition based maintenance for adding new additives packages to enable a stable hydraulic oil quality.

\section{Web-based decentralized lubricant quality monitoring system}

The integration into a suitable communication structure and the realization of an online monitoring system offers an interesting practice-oriented utilization of the oil sensor system. This is briefly discussed below.

Preferred areas of application of the sensor system are energy production and automated technical plants that are operated locally, like e.g. wind turbines, generators, hydraulic systems or gearboxes. Plant employers are interested in continuous automated in vivo examination of the oil quality rather than interrupting the operation for regular sampling. Online oil status monitoring significantly improves the economic and ecological efficiency by increasing operating safety, reducing down times or adjusting oil change intervals to actual requirements. Once the oil condition monitoring sensors are installed on the plants, the measuring data can be displayed and evaluated elsewhere. A flexible decentralized monitoring system also enables the analysis of measuring signals and monitoring of the plants by external providers. A user-orientated service ensuring the quantitative evaluation of changes in the oil-machine system, including the recommendation of resulting preventive maintenance measures, relieves plant operators, increases reliability and saves costs. 
In a web-based decentralized online oil condition monitoring system, the sensor signals are preferably transferred through the Internet to a database server and recorded on an HTML page as user interface [5].

Following authentication, a simple web browser permits access via the wired or wireless LAN. In case of alarm signals, an immediate automated generation of warning messages, for instance by e-mail or SMS, is possible from any computer with Internet connection. Fig. 10 shows the WearSens ${ }^{\circledR}$ sensor with the triple plate design $[6,7]$.

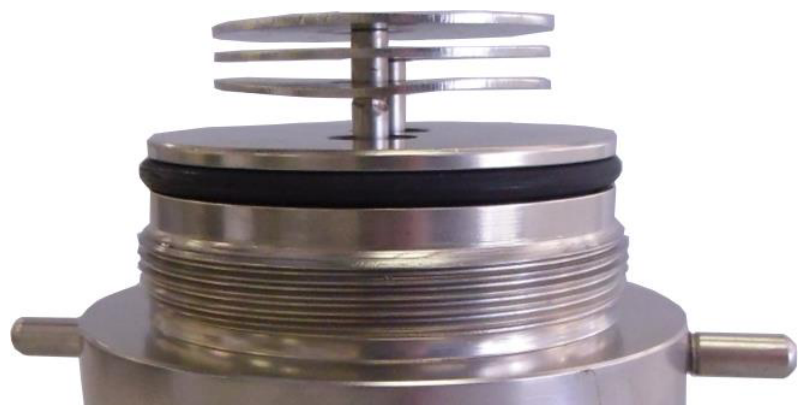

Figure 10. Detail of the tripe plate design of the WearSens ${ }^{\circledR}$ base sensor.

\section{Summary}

The online diagnostics system measures components of the specific complex impedance of oils. For instance, metal abrasion due to bearing wear at the tribological contact, broken oil molecules, acids or oil soap cause an increase in electrical conductivity that directly correlates with the degree of pollution of the oil. The dielectrical properties of the oils are especially determined by the water content, which, in the case of products that are not enriched with additives, becomes accessible by an additional accurate measurement of the dielectric constant. In the case of oils enriched with additives, statements on the degradation of additives can also be deduced from recorded changes in the dielectric constant.

Indication of damage and wear is measured as an integral factor of, e.g., the degree of pollution, oil aging and acidification, water content and the decomposition state of additives or abrasion of the bearings. It provides informative data on lubricant aging and material loading as well as the wear of the bearings and gears for the online operative monitoring of components of machines. Additional loading, for instance, by vibration induced mixed friction in rolling-sliding contact (rolling bearings, gears, cams, etc.) causes faster oil aging. Verified in roller bearing rig tests, the oil suffers from incipient resinification and significant acidification, as proven by infrared spectroscopy of used lubricant.

For an efficient machine utilization and targeted damage prevention, the new WearSens ${ }^{\circledR}$ online condition monitoring system offers the prospect to carry out timely preventative maintenance on demand rather than in rigid inspection intervals. The determination of impurities or reduction in the quality of the lubricants and the quasi continuous evaluation of the bearing and gear wear and oil aging meet the holistic approach of a real-time monitoring of a change in the condition of the oilmachine system.

The measuring signals can be transmitted to a web-based condition monitoring system via LAN, WLAN or serial interfaces of the sensor system. The monitoring of the tribological wear mechanisms during proper operation below the tolerance limits of the components then allows preventive, condition-oriented maintenance to be carried out, if necessary, long before regular overhauling, thus reducing outages caused by wear while simultaneously increasing the overall lifetime of the oil-machine system.

The oil sensor system was installed into an oil circuit of a hydraulic actuator system for ground resonance excitation performing a long term analysis of the hydraulic oil quality. The functionality of the introduced electric online condition monitoring sensor system is tested successfully. The evaluation of the experiment is presented [8].

\section{Acknowledgements}

The authors wish to thank the technical assistance of Luis Figuerido from CENER, Spain.

\section{References}

1. M. Mauntz, J. Gegner and U. Kuipers, Ölsensorsystem zur Echtzeit-Zustandsüberwachung von technischen Anlagen und Maschinen, Technisches Messen 77, 2010, pp. 283-292

2. M. Mauntz, U. Kuipers, ÖlsensorsystemSensorsystem zur Messung von Komponenten der komplexen Impedanz elektrisch gering leitender und nichtleitender Fluide, dessen Realisierung und Anwendung, Patentanmeldung Nr. $10 \quad 2008 \quad 047$ 366.9, Anmelder: cmc Instruments $\mathrm{GmbH}$, Deutsches Patentamt, München, Anmeldetag: 15. 9. 2008

3. M. Mauntz, U. Kuipers, Verfahren, Schaltungsanordnung, Sensor zur Messung physikalischer Größen in Fluiden sowie deren Verwendung, Europäische Patentanmeldung Nr. EP 09000244, Europäisches Patentamt, München, 9. 1. 2009

4. MTS, Wind Turbine Testing solutions, Minnesota, 2012

5. M. Mauntz, U. Kuipers, J. Gegner, New Electric Online Oil Condition Monitoring Sensor - an Innovation in Early Failure Detection of Industrial Gears, The 4th International Multi-Conference on Engineering and Technological Innovation July 19th - July 22nd, 2011, Orlando, Florida, USA 2011, Proceedings Volume I, International Institute of Informatics and Systemics, Winter Garten, FL, USA, 2011, pp. 238-242 
6. M. Mauntz, U. Kuipers, J. Gegner, High-precision online sensor condition monitoring of industrial oils in service for the early detection of contamination and chemical aging, Sensor + Test Conferences 7.9.6.2011, Nürnberg, AMA Service GmbH, Wunstorf, 2011, pp. 702-709

7. M. Mauntz, J. Gegner, S. Klingauf, U. Kuipers, Continuous Wear Measurement in Tribological Systems to Control Operational Wear Damage with a new Online Oil Sensor System, TAE Technische Akademie Esslingen, 19th International Colloquium Tribology, Esslingen, January 21-23, 2014, 23.01.2014

8. M. Mauntz, U. Kuipers, J. Peuser, Continuous, online detection of critical operation conditions and wear damage with a new oil condition monitoring system, WearSens ${ }^{\circledR}$, 14th International Conference on Tribology - SERIATRIB '15 Proceedings, Belgrad, Serbian Tribology Society Kragujevac, University of Belgrade, Faculty of Mechanical Engineering, Belgrade, 13-15 Mai 2015, ISBN: 97886-7083-857-4, S. 283-288 